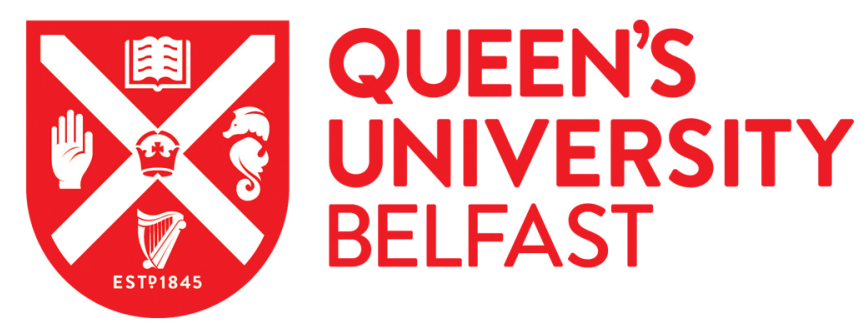

\title{
Bidirectional DC-DC Resonant Converter Design for Electric Vehicle Charging Stations Integration to MVDC Grids
}

\author{
Alhurayyis, I., Elkhateb, A., \& Morrow, D. J. (2020). Bidirectional DC-DC Resonant Converter Design for Electric \\ Vehicle Charging Stations Integration to MVDC Grids. In 9th International Conference on Renewable Energy \\ Research and Applications: Proceedings (pp. 236-241). (International Conference on Renewable Energy \\ Research and Application (ICRERA): Proceedings). Institute of Electrical and Electronics Engineers Inc.. \\ https://doi.org/10.1109/ICRERA49962.2020.9242656 \\ Published in: \\ 9th International Conference on Renewable Energy Research and Applications: Proceedings
}

Document Version:

Peer reviewed version

Queen's University Belfast - Research Portal:

Link to publication record in Queen's University Belfast Research Portal

Publisher rights

Copyright 2020 IEEE. This work is made available online in accordance with the publisher's policies. Please refer to any applicable terms of use of the publisher.

\begin{abstract}
General rights
Copyright for the publications made accessible via the Queen's University Belfast Research Portal is retained by the author(s) and / or other copyright owners and it is a condition of accessing these publications that users recognise and abide by the legal requirements associated
\end{abstract} with these rights.

Take down policy

The Research Portal is Queen's institutional repository that provides access to Queen's research output. Every effort has been made to ensure that content in the Research Portal does not infringe any person's rights, or applicable UK laws. If you discover content in the Research Portal that you believe breaches copyright or violates any law, please contact openaccess@qub.ac.uk. 


\section{Bidirectional DC-DC Resonant Converter Design for Electric Vehicle Charging Stations Integration to MVDC Grids}

\author{
Ibrahim Alhurayyis \\ School of Electronics, Electrical \\ Engineering and Computer Science \\ (EEECS) \\ Queen's University Belfast, \\ United Kingdom \\ ialhurayyis01@qub.ac.uk
}

\author{
Ahmad Elkhateb \\ School of Electronics, Electrical \\ Engineering and Computer Science \\ (EEECS) \\ Queen's University Belfast, \\ United Kingdom \\ a.elkhateb@qub.ac.uk
}

\author{
D John Morrow \\ School of Electronics, Electrical \\ Engineering and Computer Science \\ (EEECS) \\ Queen's University Belfast, \\ United Kingdom \\ dj.morrow@qub.ac.uk
}

\begin{abstract}
The extensive use of electric vehicles (EVs) needs ultra-fast-charging stations with high charging power greater than $22 \mathrm{~kW}$ ( P $\left._{\text {Charging }}>22 \mathrm{~kW}\right)$. Medium voltage direct current (MVDC) grids can provide the best solution for the high demand of EVs and fast-charging stations infrastructures with the existing distribution grids. The resonant bidirectional dual active bridge (DAB) DC-DC converter can be a promising technology in integrating an electric vehicle charging station (EVCS) with MVDC grid. This work focuses on the converter design with voltage control and stability by applying two different control strategies mainly: PI control and sliding mode control (SMC). All simulations will be performed in order to present the feasibility of the proposed solution and compare the results of each control methods. This comparison, for the first time, in the medium voltage level can open new insights for using nonlinear control methods such as SMC to ensure stability and obtain better dynamic performance
\end{abstract}

Keywords-MVDC; electric vehicles charging stations (EVCSs), DAB converter, PI, sliding mode control (SMC)

\section{INTRODUCTION}

With the widespread using of electric vehicles (EVs), charging time reduction is the main challenge. The level 3 of fast charging can reduce the charging time to less than 15 minutes with the power rating in the range of $50-350 \mathrm{~kW}$ [1][3]. In the near future, the power demand for feeding these EVs may exceed the capacity of existed grids since the charging power depends on the capacity of electric cars that tends to be $60 \mathrm{kWh}$. Thus, Ultra-fast charging stations with charging power greater than $22 \mathrm{~kW}\left(\mathrm{P}_{\text {Charging }}>22 \mathrm{~kW}\right)$ that can use MVDC grids are considered as an optimal solution to supply charging loads [4]-[5].

Dual active bridge (DAB) DC-DC converter is a promising topology for MVDC grids. It has been getting a considerable attention because of its features, such as simplicity, galvanic isolation, high efficiency, and soft switching capability [6]. However, the soft switching is limited in wide voltage applications. Also, the conventional DAB is suffered from the high losses of turning off and high revers energy. A wide range of control techniques have been proposed in the literature [7]-[11]. Although some control methods have been proposed to ensure the soft switching, they are complicated, and the soft switching can be achieved among certain operation zones [6], [12], [13].
Bidirectional resonant converters become a preferable topology in terms of DC-DC applications. Resonant converters provide several advantages such as soft switching capability for all switches, high frequency operations, and high efficiency with low EMI and few components [14], [15].

Several DC-DC converters for exploiting the maximum power have been discussed in the literature [16]-[18]. DC-DC resonant converters that utilize resonant compensation networks without additional resonant tanks have been discussed in [19]. LLC resonant converter consists of 3 resonant elements which is able to achieve the zero-voltage switching (ZVS) for switches in the inverter side. The bidirectional power flow necessitates to replace the diodes in the rectifier bridge with fully controlled semiconductor devices [14]. However, in the reverse mode, the voltage gain is different. A symmetric resonant tank in CLLLC has been proposed, but this structure can result in the volume increase and possibility of errors in the analysis and design [20]. In contrast to the CLLLC structure, a CLLC topology with 4 resonant components can achieve the ZVS in the inverter side at full-load range and the zero-current switching (ZCS) in the rectified side with a certain range of load. In addition, the similar voltage gain of the CLLLC configuration can be accomplished with neglecting one resonant inductor [14].

Thus, this work is to employ the CLLC resonant DAB DCDC converter to couple the EV fast charging station to MVDC grids. Section II presents the EV charging station and it is followed by the proposed CLC resonant DAB in Section III. The control methods for the resonant $\mathrm{DAB}$ converter and $\mathrm{EV}$ charging unit are covered in Section IV. The simulation results are discussed in Section V.

\section{EV CHARGING DESIGN}

Before designing the charging station, there a few aspects should be considered as the following [4]:

- Estimating the power demand of charging slots.

- The rate of maximum charging power for each vehicle.

- Network parameters, such as the power levels and nominal voltage. 


\section{A. EV Charging Station Rating Power}

The charging station consists of two charging units to allow charging two electric vehicles simultaneously. The station is designed when all vehicles are charged in the fast charging mode. Thus, each vehicle needs a charging power equal to [21],[22]:

$$
P_{\text {charging }}=V_{\max } I_{\max }=400 * 200=80 \mathrm{~kW}
$$

The nominal apparent charging power is selected to be:

$$
A=160 \mathrm{kVA}
$$

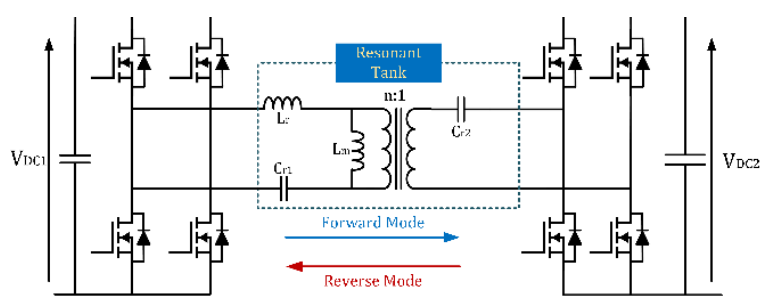

Fig. 1. CLLC DC-DC dual active bridge (DAB) converter.

\section{B. EV Battery Charging Converter}

The converter topology used here is the half-bridge DCDC converter in order to operate in buck mode and boost mode. In the buck mode, the battery is charged while the battery discharges in the boost mode. The boundary between the continuous and discontinuous conduction mode is necessary to determine the inductance's minimum value. The ripple current is calculated as follows [23]:

$$
\begin{gathered}
\Delta I=\frac{1}{L} \int_{0}^{t_{O N}} v_{L} d t \\
=\frac{V_{D C}-V_{n, \min }}{L} \cdot t_{O N} \\
=\frac{V_{D C}-V_{n, \min }}{L} \cdot \frac{V_{n, \text { min }}}{V_{D C} f_{S}}
\end{gathered}
$$

The minimum value of the inductance with $10 \%$ ripple of the maximum current becomes:

$$
L<\frac{V_{D C}-V_{n, \min }}{0.1 I_{\max }} \cdot \frac{V_{n, \min }}{V_{D C} f_{s}} \Rightarrow
$$

$$
L<1.7 \mathrm{mH}
$$

In the other hand, the battery capacitance can be calculated based on the peak-peak voltage ripple as the following:

$$
\Delta V_{b a t}=\frac{\Delta Q}{C_{b a t}}=\frac{1}{2} \frac{1}{C_{b a t}} \frac{\Delta I}{2} \frac{T_{s}}{2}
$$

The capacitance in case of minimum battery voltage and maximum ripple current can be expressed as

$$
C_{b a t}>\frac{1}{8} \frac{\Delta I T_{s}}{\Delta V_{b a t}} \Rightarrow C_{b a t}>111 \mu F
$$

\section{MEDIUM VOLTAGE DC-DC BIDIRECTIONAL RESONANT CONVERTER DESIGN}

Few points are necessary to be considered prior to design the resonant bidirectional converter [6], [14].

- The converter design should achieve the voltage gains of both directions of power flow.

- Choosing the high operating frequency is important for the sake of reducing the size of both magnetics and output capacitor.

- Converter design should ensure the zero-voltage switching (ZVS) for primary bridge switches and soft commutation for switches in the secondary side. That results in higher efficiency.

- Lower circulating reactive energy in the resonant network requires the small phase shift angle between the input square voltage and current.

Besides, the converter design depends on some factors. First, transformer turn's ratio should be determined. Choosing the value of magnetizing inductance is critical to meet ZVS requirements. Finally, the proper design of the resonant tank inductance and capacitors should be selected to achieve the voltage gains of both directions.

\section{A. Converter Configuration}

Fig. 3 shows the configuration of resonant DAB converter with the bidirectional power transfer. It is composed of two full-bridge converters operating under a fixed switchingfrequency. The bridges are linked with a resonant tank which includes $\mathrm{Cr}_{1}, \mathrm{Cr}_{2}$, and a transformer for galvanic isolation. In addition, it includes the leakage inductance $\mathrm{L}_{\mathrm{r}}$ and magnetizing inductance $\mathrm{L}_{\mathrm{m}}$. In the charging/forward mode, the power is conveyed from the DC bus to the charging stations, while in the reverse mode, the power is transferred from the station to the DC bus [14], [15].

\section{B. Modulation Scheme}

Many control techniques for DAB converters are proposed. The most commonly used is the single-phase shift modulation which is applying a 50\% duty ratio to all switches in both bridges. Adjusting the angle of phase-shift can control the average transferred power [6].

Another modulation method is the dual-phase shift (DPS) that offers an additional degree of freedom. This method can help in reducing the reactive power and enhancing the overall efficiency [6], [24], [25]. In the DPS, all the converter legs have different angles from each other while the gate signals are defined with $50 \%$ duty cycle. The phase shift angle can be calculated to satisfy one of the following conditions:

$$
\begin{aligned}
& 0 \leq D_{1} \leq D_{2} \leq 1 \\
& 0 \leq D_{2} \leq D_{1} \leq 1
\end{aligned}
$$

where $D_{1}$ is the inner-phase shift between the legs in each bridge and $\mathrm{D}_{2}$ is the outer-phase shift between the primary and 
secondary bridges. The average transferred power can be calculated as [25]:

$$
\begin{aligned}
& P=\frac{n V_{\text {in }} V_{o}}{2 f_{s} L}\left[D_{2}\left(1-D_{2}\right)-0.5 D_{1}^{2}\right] \text {, } \\
& 0 \leq D_{1} \leq D_{2} \leq 1 \\
& P=\frac{n V_{i n} V_{o}}{2 f_{S} L}\left[D_{2}\left(1-D_{1}-0.5 D_{2}\right)\right] \text {, } \\
& 0 \leq D_{2} \leq D_{1} \leq 1
\end{aligned}
$$

To control the power flow, the sum of both phase shifts must satisfy the following condition:

$$
D_{1}+D_{2} \leq 1
$$

The base value of transferred power can be calculated as:

$$
P=\frac{n V_{i n} V_{o}}{2 \pi f_{s} L}
$$

\section{Converter DC Gains}

The DC voltage gains for forward mode (mode-1) and reverse mode (mode-2) can be expressed as follows [14]:

$$
\begin{aligned}
& =\mid \frac{M_{\text {mode }-1}}{Z_{c r 1}+Z_{L r}+\left(R_{a c}+Z_{c r 2}\right) / / Z_{L m}} \cdot \frac{R_{a c}}{\left(R_{a c}+Z_{c r 2}\right.} \\
& M_{\text {mode }-2} \\
& =\mid \frac{\left(R_{a c}+Z_{L r}+Z_{c r 1}\right) / / Z_{L m}}{\left(R_{a c}+Z_{L r}+Z_{c r 1}\right) / / Z_{L m}++Z_{c r 2}} \cdot \frac{R_{a 1}}{\left(R_{a c}+Z_{L r}\right.}
\end{aligned}
$$

\section{The Transformer Turn's Ratio}

The transformer turn's ratio $\mathrm{n}$ can be calculated as the following expression:

$$
n=\frac{N_{1}}{N_{2}}=\frac{V_{i n}}{V_{o}}
$$

\section{E. Selection of Magnetizing inductance}

ZVS for all primary side switches can be achieved when the current through these switches is negative during the turning ON. The current magnitude is controlled by the magnetizing inductance value and dead time duration. The dead-time of this converter can be calculated in similar expression used for LLC resonant converter as,

$$
L_{m} \leq \frac{t_{\text {dead }}}{8 . f_{s} \cdot C_{\text {oss }}}
$$

where the $t_{\text {dead }}$ represents the dead-time between the upper and lower side switches in the same leg, $f_{S}$ is the switching frequency, and $C_{o s s}$ implements the equivalent output capacitance of inverting switches.

The low magnetizing inductance increase the magnetizing current which results in high conduction losses. In contrast, the large magnetizing inductance leads to low magnetizing current and that can limit the voltage gain. It is possible to design a large magnetizing inductance for long dead-time. However, this can lead to high primary side RMS current [14].

\section{F. Design the Inductance Ratio}

The inductance ratio $L_{n}$ is another factor which the voltage depends on. The small values of $L_{n}$ put the operating frequency in the narrow range. Thus, it should be as large as possible results in the wide-range operating frequency. It can be defined as [14],

$$
L_{n}=\frac{L_{m}}{L_{r}}
$$

\section{G. Design the Resonant Elements}

After determining the switching frequency, magnetizing inductance and inductance ratio, the resonant elements $\left(\mathrm{L}_{\mathrm{r}}\right.$, $\mathrm{C}_{\mathrm{r} 1}$ ) can be calculated as,

$$
\begin{aligned}
& C_{r 1}=\frac{1}{2 \pi Q f R_{a c}} \\
& L_{r}=\frac{1}{(2 \pi f)^{2} C_{r 1}}
\end{aligned}
$$

\section{H. Selecting the Capacitance Ratio and $C_{r 2}$}

Selecting a proper value of capacitance ratio $g$ to attain similar curves of the DC gains for both operating modes. It must make the curves of DC gains almost similar in the shape and amplitude. Once $\mathrm{g}$ is determined, the second resonant capacitor $\mathrm{C}_{\mathrm{r} 2}$ can be identified by,

$$
g=\frac{C_{r 2}}{C_{r 1}}
$$

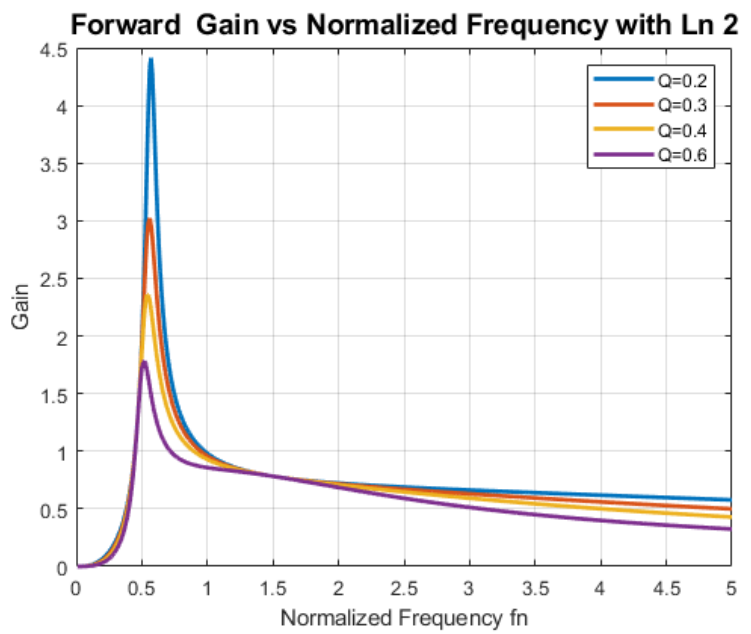

Fig. 2. Forward gain with different values of Q.

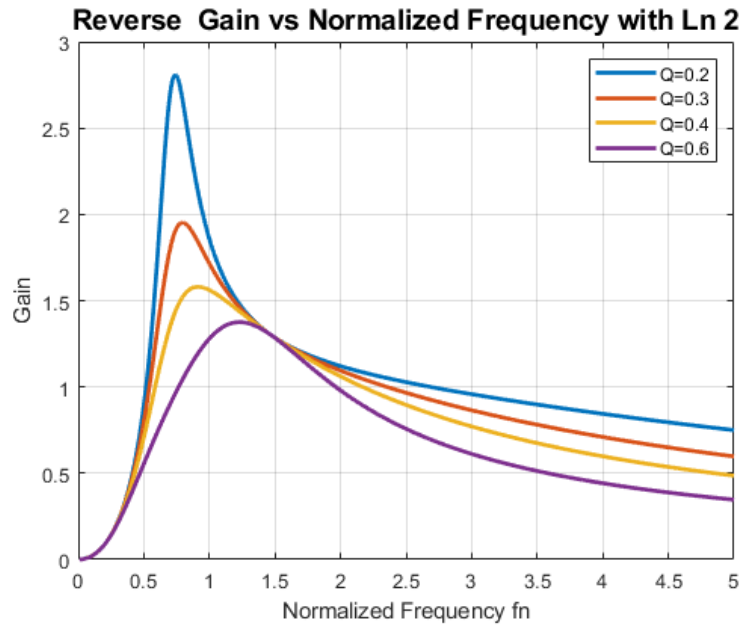

Fig. 3. Reverse gain with different values of $\mathrm{Q}$. 
It can be clearly seen that the highest gains for forward mode and reverse mode can be achieved when Ln equals to 2 and $\mathrm{Q}$ is about 0.3 .

\section{CONTROL SYSTEM}

\section{A. DC-DC DAB Converter Control}

The bidirectional DC-DC converters have nonlinear elements which results in non-linear dynamic equation. Thus, the nonlinear control methods would be an appropriate choice.

1) Proportional Integral (PI) Controller: This control scheme is very common. It is imple and easy to implment but it has some shortcomings such as mxiumum overshooting with high settling time and low robustness against uncertainties. Therefore, its response is low to fast changes. It is used to control the outut voltage. The input to the PI is the error voltage resulted from the subtracting the desired voltage and the measureed output voltage. The PI output signal withe is the sum of both proportional and integral of error signal represtns the duty-cycle of a pulse width modulation (PWM) [26], [27]. The arrangment of PI controller is shown in fig. 4.

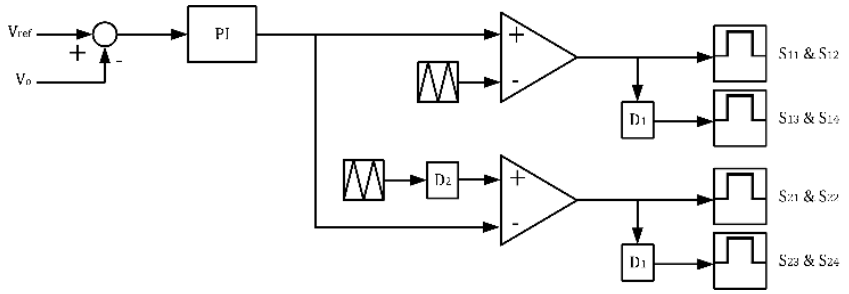

Fig. 4. PI control scheme for dual-phase shift (DAB) converter.

2) Sliding Mode Control (SMC): The SMC is one of nonlinear control startegies which is advantageous in terms of fast rsponse during finite-time and rubstness in case of parameter variations or perturbation. The bidirectional DCDC converters have nonlinear elements which results in nonlinear dynamic equation. The SMC is beneficial for variations and disturbnces with low sensitivity. The oscillating behavior is inherent in the SMC and it is called chattering phenomena. In general, the SMC involves two control loops: the inner current and outer voltage control loops. Fig. 5 shows the SMC arrangement. In the SMC, the sliding line can decide switching state $\mathrm{u}$ that is corresponding the turning On and OFF of the switch. The sliding surface $S$ can be represnted as a linear set of state variables. The switching function can be expressed as [28],

$$
S=\alpha_{1} x_{1}+\alpha_{2} x_{2}+\ldots+\alpha_{n} x_{n}=\alpha^{T} x=0
$$

where $\alpha^{\mathrm{T}}$ represents a vector of the sliding surface coefficients.

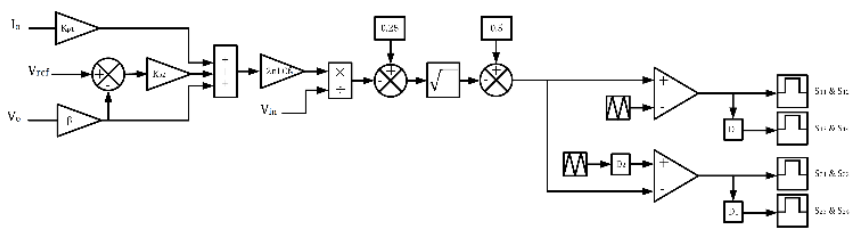

Fig. 5. Sliding mode control scheme for (DAB) converter.
The equation above describes the sliding line that passes the phase plane via the origin. The origin is called the stable operating point where the voltage error equals to zero. It can take a role of acting as a boundary by splitting the phase plane into two regions. Each region is allocated for a switching state to drive or steer the phase trajectory to the sliding line. The system would be stable if the phase trajectory reaches and follows the sliding line in the direction of the origin.

The sliding mode control is combined with direct power control. Since the filter capacitor at the output side is constant, the relationship between the power and energy inside the capacitor can be interpret as,

$$
\begin{aligned}
\frac{d w_{C}}{d t}=\frac{d\left(0.5 C v_{o}^{2}\right)}{d t} & =P-P_{o}=P-v_{o}(t) i_{o}(t) \\
\frac{d v_{o}}{d t} & =P-\frac{i_{o}(t)}{C}
\end{aligned}
$$

where $\mathrm{P}$ is calculated in (6).

The output voltage error and its integral term can be used in design the controllers to rearrange (20) as [28],

$$
\begin{aligned}
& P=\frac{i_{o}(t)}{C}+\frac{\alpha_{1}}{\alpha_{2}}\left(v_{o}^{*}-v_{o}(t)\right) \\
& +\frac{\alpha_{3}}{\alpha_{2}} \int\left(v_{o}^{*}-v_{o}(t)\right) d t \\
& \frac{\alpha_{1}}{\alpha_{2}}=\frac{10}{T_{s}} \\
& \frac{\alpha_{3}}{\alpha_{2}}=\frac{25}{\zeta^{2} T_{s}^{2}} \\
& K_{p 1}=\beta L_{r}\left(\frac{\alpha_{1}}{\alpha_{2}}-\frac{1}{R_{a c} C}\right) \\
& K_{p 2}=L_{r} C \frac{\alpha_{3}}{\alpha_{2}} \\
& v_{c}=\left[-\beta L_{r}\left(\frac{\alpha_{1}}{\alpha_{2}}-\frac{1}{R_{a c} C}\right) i_{c}+L_{r} C \frac{\alpha_{3}}{\alpha_{2}}\left(V_{r e f}\right.\right. \\
& \left.\left.-\beta v_{o}\right)+\beta v_{o}\right] \\
& f_{B W}=f_{S} * \frac{1}{20} \\
& \omega_{n}=2 \pi f_{B W} \\
& T_{s}=\frac{4}{\zeta \omega_{n}} \\
& \beta=\frac{V_{\text {ref }}}{V_{o}}
\end{aligned}
$$


TABLE I. LITHIUM-ION BATTERY PARAMETERS

\begin{tabular}{|c|c|}
\hline Parameters & Values \\
\hline Nominal Voltage $\mathrm{V}_{\mathrm{n}}$ & $400 \mathrm{~V}$ \\
\hline Battery capacity & $40 \mathrm{Ah}$ \\
\hline Open circuit voltage $\mathrm{V}_{\mathrm{n}, \max }$ & $454.3 \mathrm{~V}$ \\
\hline Internal resistance & $0.1 \Omega$ \\
\hline Minimum cut-out voltage $\mathrm{V}_{\text {bat, min }}$ & $300 \mathrm{~V}$ \\
\hline
\end{tabular}

where $v_{0}^{*}$ is the output voltage reference and $f_{B W}$ is the bandwidth of closed-loop.

\section{B. EV Charging Converter Control}

The battery charging control uses two control methods: constant current $(\mathrm{CC})$ and constant voltage (CV). The battery will be charged by applying the constant current control in the beginning and then switching to voltage control scheme in order to prevent the high currents injection. In the constant current strategy, the battery operates as a current source while it mimics as a voltage source in the constant voltage method. The attained duty ratio defines which operation mode where the boost mode is defined by the CC scheme and the buck mode is realized by applying the CV method [22], [23].

\section{COMPARISON AND DISCUSSION}

Simulations are carried out for CLLC DAB using the PI and SM control methods. The system is composed of 4 CLLC $\mathrm{DAB}$ converters connected in the input parallel output parallel (IPOP) to feed two charging units for two electric vehicle. During the simulation, the two EVS start charging at $\mathrm{t}=0.1 \mathrm{~s}$ and then discharging at $\mathrm{t}=0.3 \mathrm{~s}$ until $\mathrm{t}=0.352 \mathrm{~s}$ to turn into charging mode. The two control methods have been investigated to offer maximum effort for ensure stability.

The obtained waveforms presented below are discussed. It can be clear that the settling time of SMC is shorter compared with the PI control. Therefore, a better dynamic response can be attained with SMC.

TABLE II. DC-DC RESONANT DAB CONVERTER PARAMETERS

\begin{tabular}{|c|c|}
\hline Parameters & Values \\
\hline $\mathrm{V}_{\text {in }}$ & $3000 \mathrm{~V}$ \\
\hline $\mathrm{V}_{\text {out }}$ & $1500 \mathrm{~V}$ \\
\hline $\mathrm{n}$ & 2 \\
\hline $\mathrm{R}_{\mathrm{ac}}$ & 73 \\
\hline $\mathrm{C}_{\mathrm{r} 1}$ & $129.77 \mathrm{nF}$ \\
\hline $\mathrm{L}_{\mathrm{r}}$ & $62.3 \mu \mathrm{H}$ \\
\hline $\mathrm{L}_{\mathrm{m}}$ & $124.6 \mu \mathrm{H}$ \\
\hline $\mathrm{C}_{\mathrm{r} 2}$ & $129.77 \mu \mathrm{F}$ \\
\hline $\mathrm{f}_{\mathrm{s}}$ & $56 \mathrm{kHz}$ \\
\hline $\mathrm{C}_{\mathrm{o}}$ & $1250 \mu \mathrm{F}$ \\
\hline
\end{tabular}

\section{A. PI Controller}

The output voltage and current of the DAB with PI controller are presented in fig. 6 where VDC ranges from $1466 \mathrm{~V}$ to $1472 \mathrm{~V}$ with no load and from $1452 \mathrm{~V}$ to $1460 \mathrm{~V}$ when charging the EVs. The settling time is $0.009 \mathrm{~s}$. That is followed by the primary and secondary voltage waveforms of the transformer under dual-phase shift modulation in fig. 7. Also, the voltage, current, and state of charge (SoC) of EVs batteries are presented in fig. 8 .

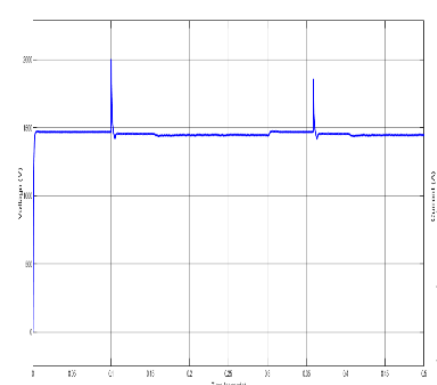

(a)

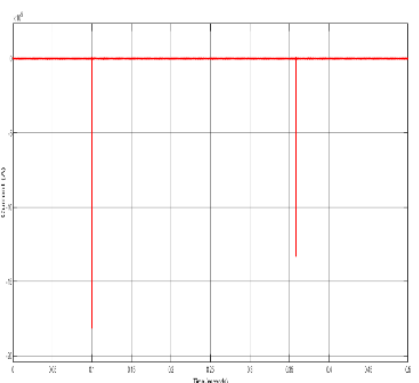

(b)
Fig. 6. DC link (a) voltage and (b) current with PI controller.

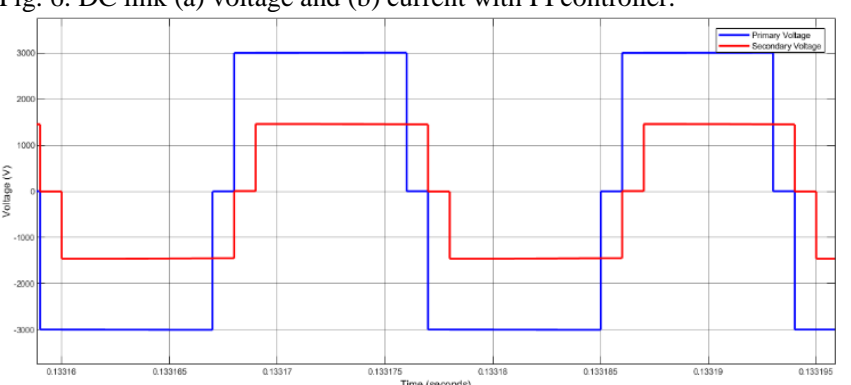

Fig. 7. Waveforms of primary and secondary voltages.

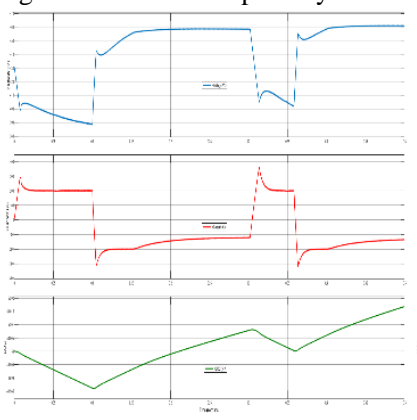

(a)

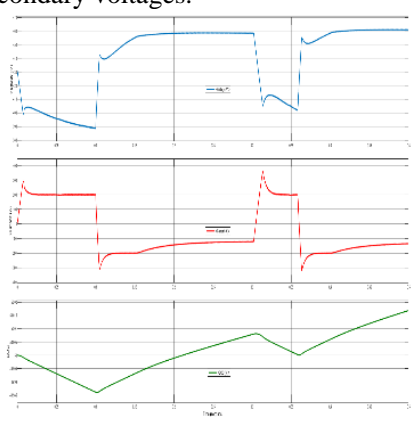

(b)
Fig. 8. Voltage, current, and SoC of the batteries of (a) EV1 and (b) EV2.

\section{B. Sliding Mode Control}

The sliding coefficients are calculated as $\mathrm{K}_{\mathrm{pl}}=0.1094$ and $\mathrm{K}_{\mathrm{p} 2}=0.019549$. The $\mathrm{V}_{\text {ref }}$ is chosen to be 500 and therefore $\beta$ equals to $1 / 3$. The figures below present the DC link voltage and current, the low and high voltage sides of the DAB, and variations of batteries parameters. The settling time is 0.0075 $\mathrm{s}$ which is shorter compared with PI controller. The variations in the DC link voltage follow those in PI.

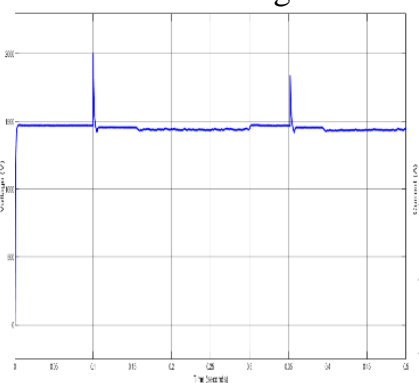

(a)

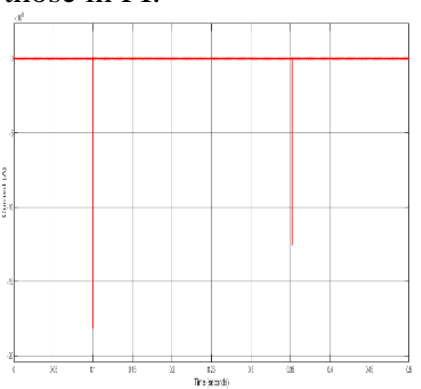

(b)
Fig. 9. DC link (a) voltage and (b) current under SMC. 
Both control methods offer similar performance in the steady state region. However, the SMC can provide better performance with variations rather than the PI. That because of the fast response and the low settling time.

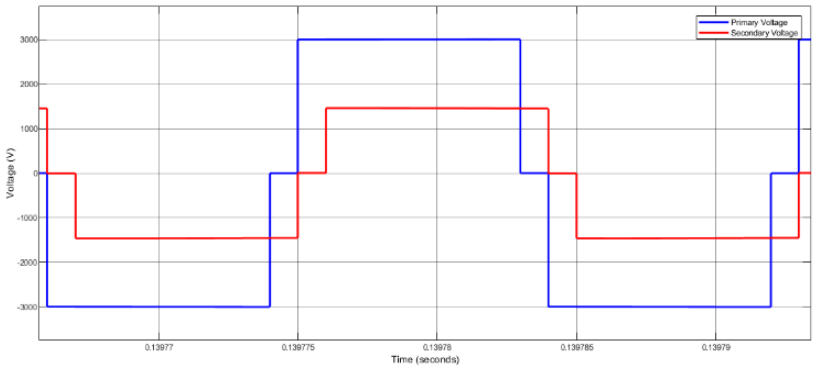

Fig. 10. Waveforms of primary and secondary voltages using SMC.

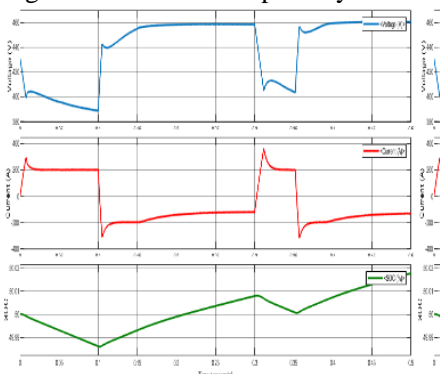

(a)

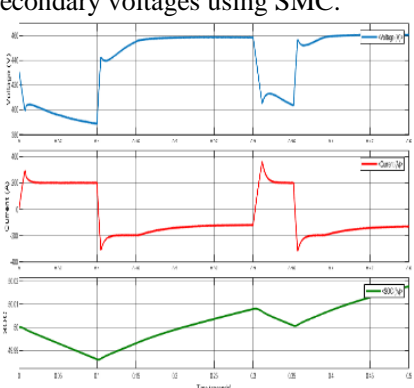

(b)
Fig. 11. Voltage, current, and SoC of the batteries of (a) EV1 and (b) EV2.

\section{CONCLUSION}

In this paper, a comparison between the PI and sliding mode controllers have been presented for the resonant bidirectional DAB converter. The steps start from designing the resonant tank of DAB converter to deriving the mathematical equations for SMC and then it is implemented using MATLAB/Simulink. The results show that settling time of the SMC is shorter than that of the PI control. Therefore, a better dynamic response can be attained with SMC.

\section{REFERENCES}

[1] M. Yilmaz and P. T. Krein, "Review of Battery Charger Topologies, Charging Power Levels, and Infrastructure for Plug-In Electric and Hybrid Vehicles," IEEE Trans. Power Electron., vol. 28, no. 5, pp. 2151-2169, May 2013.

[2] "Chademo Brochures," Chademo Association \& Protocol, Mar-2018. [Online]. Available: https://www.chademo.com/aboutus/brochures/

[3] “Combined Charging System (CCS)," ChARIN, 23-Jul-2018. [Online] Available: https://www.charinev.org/faq/.

[4] M. Stieneker, B. Mortimer, A. Hinz, A. Müller-Hellmann, R. De Doncker, "MVDC Distribution Grids for Electric Vehicle FastCharging Infrastructure," International Power Electron. Conference (IPEC-Niigata 2018 -ECCE Asia), Niigata, 2018, pp. 598-606.

[5] J. Hu, M. Stieneker, P. Joebges, R. De Doncker, "Intelligent DC-DC Converter Based Substations Enable Breakerless MVDC Grids," IEEE Electronic Power Grid (eGrid), Charleston, SC, 2018, pp. 1-5.

[6] B. Zhao, Q. Song, W. Liu and Y. Sun, "Overview of Dual-ActiveBridge Isolated Bidirectional DC-DC Converter for High-FrequencyLink Power-Conversion System," IEEE Trans. Power Electron., vol. 29, no. 8, pp. 4091-4106, Aug. 2014.

[7] A. Elkhateb, N. Rahim, J. Selvaraj, M. Uddin, "Fuzzy-LogicController-Based SEPIC Converter for Maximum Power Point Tracking," IEEE Trans. Ind. Appl., vol. 50, no. 4, pp. 2349-2358, 2014.

[8] B. Eid, N. Rahim, A. Elkhateb, "Control Methods and Objectives for Electronically Coupled Distributed Energy Resources in Microgrids: A Review," IEEE Sys. Jour., vol. 10, no. 2, pp. 446-458, 2016.

[9] W. Issa, A. Elkhateb, M. Abusara, "Control Strategy for Uninterrupted Microgrid Mode Transfer During Unintentional Islanding Scenarios," IEEE Trans. Ind. Electron., vol. 65, no. 6, pp. 4831-4839, 2018.
[10] A. Elkhateb, N. A. Rahim and J. Selvaraj, "Optimized PID controller for both single phase inverter and MPPT SEPIC DC/DC converter of PV module," 2011 IEEE International Electric Machines \& Drives Conference (IEMDC), Niagara Falls, ON, 2011, pp. 1036-1041.

[11] A. Elkhateb, N. A. Rahim and J. Selvaraj, "Fuzzy Logic Controller for MPPT SEPIC converter and PV single-phase inverter," IEEE Symposium on Ind. Electron. Appl., Langkawi, 2011, pp. 182-187.

[12] B. Zhao, Q. Yu, W. Sun, "Extended-Phase-Shift Control of Isolated Bidirectional DC-DC Converter for Power Distribution in Microgrid," IEEE Trans. Power Electron., vol. 27, no. 11, pp. 4667-4680, 2012.

[13] B. Zhao, Q. Song, W. Liu and Y. Sun, "Overview of Dual-ActiveBridge Isolated Bidirectional DC-DC Converter for High-FrequencyLink Power-Conversion System," IEEE Trans. Power Electron., vol. 29, no. 8, pp. 4091-4106, Aug. 2014.

[14] W. Chen, P. Rong, Z. Lu, "Snubberless Bidirectional DC-DC Converter With New CLLC Resonant Tank..," IEEE Trans. Ind. Electron., vol. 57, no. 9, pp. 3075-3086, Sept. 2010.

[15] R. P. Twiname, D. J. Thrimawithana, U. K. Madawala and C. A. Baguley, "A Dual-Active Bridge Topology With a Tuned CLC Network," IEEE Trans. Power Electron., vol. 30, no. 12, pp. 65436550, Dec. 2015.

[16] A. Elkhateb, N. A. Rahim and J. Selvaraj, "Cascaded DC-DC Converters as a Battery Charger and Maximum Power Point Tracker for PV Systems," 2013 International Renewable and Sustainable Energy Conference (IRSEC), Ouarzazate, 2013, pp. 426-429.

[17] A. Elkhateb, N. A. Rahim, J. Selvaraj and B. W. Williams, "DC-to-DC Converter With Low Input Current Ripple for Maximum Photovoltaic Power Extraction," IEEE Trans. Ind. Electron., vol. 62, no. 4, pp. 2246-2256, April 2015.

[18] H. A. Attia, T. K. S. Freddy, H. S. Che, W. P. Hew and A. Elkhateb, "Confined Band Variable Switching Frequency Pulse Width Modulation (CB-VSF PWM) for a Single-Phase Inverter With an LCL Filter," IEEE Trans. Power Electron., vol. 32, no. 11, pp. 8593-8605, Nov. 2017.

[19] A. Elkhateb, G. Adam and D. J. Morrow, "DC-to-DC Converter Topologies for Wireless Power Transfer Electric Vehicles," IECON 2019 - 45th Annual Conference of the IEEE Ind. Electron. Society, Lisbon, Portugal, 2019, pp. 1665-1669.

[20] Z. U. Zahid, Z. M. Dalala, R. Chen, B. Chen and J. Lai, "Design of Bidirectional DC-DC Resonant Converter for Vehicle-to-Grid (V2G) Applications," IEEE Trans. Transportation Electrification, vol. 1, no. 3, pp. 232-244, Oct. 2015.

[21] G. Angelov, M. Andreev, N. Hinov, "Modelling of Electric Vehicle Charging Station for DC Fast Charging," 41st International Spring Seminar on Electronics Technology (ISSE), Zlatibor, 2018, pp. 1-5.

[22] A. Arancibia and K. Strunz, "Modeling of an electric vehicle charging station for fast DC charging," 2012 IEEE International Electric Vehicle Conference, Greenville, SC, 2012, pp. 1-6.

[23] V. Castiglia, P. Livreri, R. Miceli, F. R. Galluzzo, G. Santelia, G. Schettino, "Design and simulation of a fast DC recharging station for $\mathrm{EV}, "$ IEEE 6th Int. Conference on Renewable Energy Research and Applications (ICRERA), San Diego, CA, 2017, pp. 1198-1203.

[24] H. Bai, C. Mi, "Eliminate Reactive Power and Increase System Efficiency of Isolated Bidirectional Dual-Active-Bridge DC-DC Converters Using Novel Dual-Phase-Shift Control," IEEE Trans. Power Electron., vol. 23, no. 6, pp. 2905-2914, Nov. 2008.

[25] X. Liu et al., "Novel Dual-Phase-Shift Control With Bidirectional Inner Phase Shifts for a Dual-Active-Bridge Converter Having Low Surge Current and Stable Power Control," IEEE Trans. Power Electron., vol. 32, no. 5, pp. 4095-4106, May 2017.

[26] N. Hou and Y. Li, "The Comprehensive Circuit-Parameter Estimating Strategies for Output-Parallel Dual-Active-Bridge DC-DC Converters With Tunable Power Sharing Control," IEEE Trans. Ind. Electron., vol. 67, no. 9, pp. 7583-7594, Sept. 2020.

[27] H. Qin and J. W. Kimball, "Closed-Loop Control of DC-DC DualActive-Bridge Converters Driving Single-Phase Inverters," IEEE Trans. Power Electron., vol. 29, no. 2, pp. 1006-1017, Feb. 2014.

[28] Siew-Chong Tan, Y. Lai, C. Tse, "A unified approach to the design of PWM-based sliding-mode voltage controllers for basic DC-DC converters in continuous conduction mode," IEEE Trans. Circuits and Systems I: Regular Papers, vol. 53, no. 8, pp. 1816-1827, Aug. 2006. 